\title{
VISUAL EFFECTS CINEMATOGRAPHY \\ THE CINEMATOGRAPHER'S FILMIC TECHNIQUE FROM TRADITIONAL TO DIGITAL ERA
}

\author{
Nawal Mohamed Salah ELDIN \\ College of Applied Sciences,Ibri, Sultanate of Oman \\ nawals.ibr@cas.edu.om
}

\begin{abstract}
Special effects cinematography is as old as cinema itself. The cinematographer had a major role in making the special effects scene either by making the whole effect in camera or combined with the optical effects in laboratory after shooting. A question pops up after the digital revolution: Does the cinematographer have the same role as before? Is there a need to adopt new techniques to master the cinematographer work in the digital era? This paper attempts to explore the differences between the conventional and the digital visual effects from the cinematographer's technical point of view, based on a comparative study. Before the digital era most of the effects were done by the camera or in the laboratory. Nowadays, however, there are new tools and techniques such as digital visual effects that overruled the cinema industry, sometimes the only live-action elements are the actors. The term CGI (Computer Generated Images) is currently well known to many people and filming is only the first step to be followed by many other procedures. The mentioned procedures are called post production, which is the region where most of the visual effects creation takes place.
\end{abstract}

Keywords: Cinematography, Digitalization, Visual Effects

\section{INTRODUCTION}

'Special effects' are created where techniques beyond the 'normal' film making procedures are used. That is to say when things might be more complex or time-consuming or involve 'special' techniques. 'Special' effects, as currently defined, would be where modifications are made physically to any of these elements or the interfaces between them.[1] visual effects (also called optical or photographic effects) are special effects achieved with the aid of photographic or digital technology, occurring after the principal photography, or main shooting, of a film. Includes miniatures, optical and digital effects, matte paintings, stopmotion animation, and computer-generated imagery (CGI).[2]

\section{VISUAL EFFECTS: THE DEFINITION}

Until fairly recently, the art and craft of visual effects went by the name special photographic effects because the work was accomplished photographically on film and relied heavily on special optical cameras called optical printers. Most of the serious visual effects work took place in postproduction. Nowadays we simply call it visual effects. But even defining a visual effect is far from straightforward. For one thing, some people include visual effects in the general category of special effects, while others may refer to them as special visual effects.

Before the introduction of computer graphics, it was relatively easy to say what a visual effect was: If a shot required some sort of treatment in postproduction and rephotographing on an optical printer, it was called a "special photographic effect." John Dykstra, one of the top visual effects supervisors in the business today (and one of the main creative forces behind the visual effects for the seminal film Star Wars of 1977), once defined a visual effect as "two or more elements of film combined into a single image." [3] 
AS described by the Visual Effects Society: Visual effects is the term used to describe any imagery created, altered, or enhanced for a film or other moving media that cannot be accomplished during live-action shooting. In other words, much of the art of visual effects takes place in post-production, after primary image capture is complete. Visual effects can be added to live-action capture through techniques such as matte painting; rear- and front-screen projection; miniature or forced perspective sets; computer graphic objects, characters, and environments; and compositing of disparate images recorded in any number of ways.[4] From both points of view we can reach that: A visual effect is the manipulation of moving images by photographic or digital means that creates a photorealistic cinematic illusion that does not exist in the real world.

\section{VISUAL EFFECTS, THE BEGINNING AND DEVELOPMENT}

\subsection{The Sielent Era}

Visual effects have been a part of the filmmaker's creative toolbox almost from the first time a cinematographer cranked a handle on a wooden camera back in the 1890s. The first known visual effect that seems to have survived was created in 1895 in a short film called The Execution of Mary, Queen of Scots. Some film makers like Geoges Melies accidently discovered techniques accidently like the substitution shot which he discovered when his camera jammed, he soon turned this technique into an art form, many of the techniques Melies invented are still implemented among them stop motion animation and double exposure.[5]

In the very first years of commercial filmmaking, 1895 to 1905, any visual effect was limited to what could be done in-camera, which included fairly rudimentary effects such as substitution shots (stopping the camera and changing the scene before starting it again) or simple frame splits. In this latter technique, the first part of the effect would be shot, during which hand-drawn mattes would be slipped into the light path before the film plane, placed in front of the camera on stands, or even attached directly to the lens of the camera. The film was wound back to the starting point of the scene and the second element then exposed onto the film in the area that had no exposure from the black matte. In these early days, the camera was always locked down, which made such effects possible. [6]

Any good cameraman was capable of producing number of 'live' tricks during the handcranked filming process including the basic fading and iris effects. Cameramen could also produce dissolves, by which one image merges seamlessly into another. The effect was achieved by reducing the camera's aperture at the end of a sequence to produce a fade to black, rewinding the film, starting a second exposure and opening the aperture as the new scene was shot. By varying the speed at which they cranked the camera, cameramen could also produce fast or slow motion. Methods that required running the film through the earner twice, such as split screens and double exposures, became much more practical after the introduction of a new Bell and Howell earn era in 1912. [7]

\subsection{Influence Of Sound On Visual Effects}

From about 1933, sound recording restricted filming on location, and for the next twenty years the great Hollywood outdoors would be filmed almost entirely within studio walls. The coming of sound is often held responsible for this wholesale move into the studios. For special effects departments, sound brought some new challenges. With films being made exclusively on the studio lot, effects technicians had to find ways to bring exotic and even everyday locations to the set. The technology that was developed enabled the first practical use of rear projection, a process enabling background scenery to be projected on to a screen behind actors while filming in the studio. Although rear projection often replaced the uses of travelling mattes, effects technicians continued to perfect travelling matte photography. The development of advanced optical printers, which enabled the separately filmed elements involved in travelling matte photography to be combined on film with greater control than had 
previously been possible, resulted in much-improved image quality. The optical printer also found favour in the production of many 1930s musicals whose spectacular dance sequences needed flamboyant scene transitions, such as the star-wipe and the now iconic spinning newspaper effect.[8]

\subsection{The Digital Age}

In the late 1950s and into the 1960s, John Whitney, Sr., began creating intricate and involving images using surplus analog military equipment. He photographed moving patterns of light and lit objects that were moved by these analog computers. The patterns recorded by a camera synchronized to the motion were intricate and complex. This work was the inspiration for the slitscan technique used to create the stargate sequence in the film 2001 (1968). Followed by this many visual effects artists scientists, computer engineers and companies entered the race of developing visual effects.

Major advancements in computing speed, power, and storage led to the creation of tools to record and then film out scenes captured by motion picture cameras. Visual effects facilities and visual effects and special effects artists and scientists used imagination, technical knowledge, and an amazing amount of creativity to invent and create these first tools. In the late 1980s Kodak, with collaboration from ILM, developed the technology for the first (more or less) practical film resolution scanner. Along with this invention came the development of the Cineon digital film format, which became the standard format for motion picture image recording and filming across the world.

In 1988 audiences were excited by the use of digital "morphs" in Willow. The Abyss, with its water character, and Terminator 2, featuring a fully CG leading man, opened 'in 1991. In 1992 the first attempt was made to replicate real, recognizable creatures in a feature film the penguins and bats in Batman Returns.

The years since 1993, it can be argued, included as much innovation as the previous 100 years of visual effects. Everything was open, and a legion of incredibly clever visual effects artists, scientists, and engineers redrew the landscape such that no effect was beyond our reach. We saw the world of optical printing fade from common use faster than any of us would have believed possible as digital scanners and printers, augmented by new compositing, 2D software, and fantastic developments in 3D camera and object tracking came to the fore. [9]

\section{THE VISUAL EFFETS TECHNIQUE}

Many of the conventional techniques are still in use even after the digital era, changes were made and improvements while others were replaced by digital components.

\subsection{Conventrinal Techniques In Categories}

The technique of visual effects cinematography improved over the years by many technicians and inventors, if we have a look at the conventional visual effects before implementing digital techniques; we will see that some of the effects were done by the cinematographer in the location other techniques were mainly lab process and optical printing work and sometimes a combination of the two techniques:

1- In the camera effects: in which all of the components of the final scene are photographed on the original camera negative:

A. Basic effects

1- Change in object speed, position or direction.

2- Image distortions and degradations.

3- Optical transitions.

4- Superimpositions.

5- Day- for- night photography.

B. Image replacement. 
1- Split screen photography.

2- In the camera matte shot.
3- Glass shot.

4- Mirror shot.

2- Laboratory processes: in which duplication of the original negative through one or more generation is necessary before the final effect is produced:
A. $\mathrm{Bi}-$ pack printing.
C. Travelling mattes.
B. Optical printing.
D. Aerial - image printing.

3- Combination techniques: some of the image components are photographed directly on to the final composite film, while others are produced through duplication or before shooting:

A. Background projection

1- Rear projection.

2- Front projection. [10]

Some of the visual effects can be done with several techniques and the cinematographer will decide the suitable technique. The choice of which technique to be used was mainly based on the image quality, nature of the scene, desired effect on the screen and the cost.

\subsection{Motion Controlled Cameras}

Borrowing technology from developments in sound in the late 1940s and early 1950s, visual effects artists adapted the use of synchronous motors to control pans, tilts, and dolly moves. This allowed for accurately duplicating a camera move shot on one set or location with a matching move back on the lot in the visual effects department. The gear was clumsy, and true-frame accurate recording and playback of moves was not always possible or consistent, but this precursor to motion control of film cameras provided visual effects artists with another tool to meet the growing demands of directors and camera people for more innovative shots. [11]

The use of motion-controlled cameras on set has been a great boon for actor duplication and interaction. In such scenes, the lighting is exactly the same for each take, and the two performances can be choreographed to interact precisely. A great example of this type of work can be found in the Back to the Future films (1985-1990) and The Lord of the Rings trilogy, in which actors of different scales (meaning same size actors) were made to look like giants or dwarves interacting with one another. [12]

Nowadays with the aid of computer engineering and programming the motion control camera has a system for the identical repetition of camerawork by computer control. It can, for example, be used to convert a few extras into a crowd of thousands by multiplying images, or prepare a CG background for a real scene using the sequential camera data of the original shooting. Special operations of this kind require use of a very precise motion control camera with great repeatability and cannot be performed by manual camera work. The motion control camera has, therefore, come to be regarded as an essential system for VFX productions.[13]

\subsection{Front And Rear Projection}

Front and rear projection are both in-camera compositing techniques. By this we mean that two (and rarely three) separate images are combined into one image in-camera at the time of filming. In front projection, an image is projected through a beam-splitter placed in front of the camera onto a highly reflective Scotchlite screen. In rear projection (RP), the image that is to be combined with a live-action plate is projected from the rear onto a translucent screen, and the live action plays in front of it.[14] In the pre-digital era of visual effects, front projection, rear screen projection, and "side-screen" projection were processes used for creating large-scale sets and new environments as well as for moving images out the windows of cars and planes. Although the techniques for using these tools have changed a great deal, the mechanics of the tools are basically the same, except for the new digital projection systems. In the past the background plates had to be created prior to on-set shooting, and once the on-set shooting was done, there was no fixing it in post, but it did and still does allow one to shoot many versions of the action with the subjects to give the director a variety of takes 
from which to choose. Experimentation can be done on the set with lighting and other smoke and debris elements to blend the subjects together. A good example of this is a shot from The Fugitive (1993), in which dust and debris shot from an air cannon landed on top of Harrison Ford just as a train crashed into the hillside. This was done using a front projection system that tied in all of the dust and debris on top of Harrison with the plate for integration of the elements [15] Today, front projection has virtually disappeared. And while film-based rear projection is almost extinct as well, the process has made a significant comeback in digital production, in features as well as in television and commercials. For example, the movie Get Smart (2008) used digital rear projection for dozens of shots.

\subsection{Miniatures vs. Digital Models}

The first miniature ever captured on film appears to have been the recreation in 1897 of a naval battle during the Greco-Turkish War by the French film pioneer Georges Melies. It didn't look very convincing by our standards, but miniatures have been an invaluable adjunct to live-action photography ever since. We can use miniatures in various combinations with live action or digital elements, and like other visual effects, we use miniatures when it's impossible to use the real thing because it's too expensive to film, is inaccessible, or doesn't exist in the first place. Miniatures can be either hanging in front of the camera and the live action in the back ground, or stand alone miniatures as in plane crashes and explosions or miniatures with composited elements This technique involves the compositing of a miniature either with a live-action plate, a matte painting, or some form of computer-generated background that will supplement the miniature photography. Compositing miniatures with other elements is probably the most common use of miniatures, and certainly one of the most widely used visual effects techniques. The Lord of the Rings and Harry Potter trilogies, for example, were full of such shots.

In recent years, miniatures have run into stiff competition from computer-generated environments and objects. The trend began mainly in television and gradually spread into feature films as software became more sophisticated, allowing digital artists to model, texture, and paint their creations in the computer faster and cheaper than their colleagues who were building physical models. That trend appears to have stabilized as filmmakers found that each technique has its merits, depending on the requirements of a particular project. A good example of this is the 2004 film The Aviator, a film starring Leonardo Di Caprio in the role of famed aviation pioneer Howard Hughes. That film seamlessly blended both physical and CG models. The re-creation of an aerial dogfight near the beginning of the film was realized almost entirely with CG models, while later sequences - including a spectacular sequence of Hughes crashing an experimental aircraft into a Beverly Hills neighborhood - were accomplished entirely with physical models. [16]

\subsection{Blue Screen Photography}

Blue screen process is one of the survivals techniques; it was used in conventional VFX and still in use with digital cinema. Blue screen was used as early as the silent period for generating high-quality composites on black-and-white film using the Dunning Pomeroy process. As the years progressed and color film came into being, many effects artists adapted the idea of using a blue screen to isolate an element photographically to create color composites. One of the early examples of the process was that developed by Lawrence Butler for Alexander Korda's The Thief of Baghdad in 1940. The color blue was first used for the simple reason that there is very little blue in skin tones. The blue wavelength can be isolated while still getting a fairly acceptable color rendition for faces.

The process made use of black-and-white separations. A separation is a black-and-white film that contains only one of the color components. It is made by placing the color negative in contact with black-and-white film and exposing it with a primary color. There were many problems with this method Some development were made to enhance the quality of the blue screen mattes. In the mid-1950s that a brilliant inventor named Petro Vlahos perfected the 
system and created the color-difference process. The Vlahos system was so successful that effects artists used the system for all the blue screen effects from the mid-1950s to the age of digital.[17]

With the introduction of digital cinema and the ability to make the seperation digitaly it was just easier to composite the live action with either CGI or pre-shooted live background, yet The scene shooting can makes it either easy or painfull task for the compositer.

It is the DP's job to to design the blue/green shots lighting; this involves three main tasks: matching subject lighting with the background shot, making the screen very evenly lit and ensuring that neither area interferes with the other.

The DP should fully understand certain procedures and apply them when preparing to the blue screen shot; The DP will have to:

1- Consult with the post house, determine well in advance what components are eeded and resolve the order in which elements should be most efficiently and creatively shot.

2- Coordinate the shooting of foregrounds and background to ensure that they will visually and photographically match.

3- Document details of camera, lighting and scenic set-up for use by crew shooting the foreground elements.

4- Match foreground camera and lighting to background data very precisely, with particular attention to perspective and direction of light.

5- Choose keying colour, screen method and subject positioning carefully to maximize separation, evenness and thus quality of composite.

6- Consider colour, texture and design of costumes and scenic elements in the foreground shoot to avoid technical problems.

7- Provide full information to the post-production team detailing precisely what was done during the shoot.

8- Do not degrade the foreground image by filtering or abnormal processing.[18]

\section{THE ROLE OF VFX DIRECTOR OF PHOTOGRAPHY}

After looking into some of the techniques involved in the making of the VFX scene and its development we reach the question: what is the VFX director of photography role?

The camera department consists of the director of photography (DP) and a crew of camera operators and camera assistants. The DP is in charge of all photography, including lighting and composition. The gaffer, head of the electrical department, works very closely with the DP on the lighting. Whatever is captured by the camera system (film or digital) will be used as the basis for the visual effects plates and will also be used as a look reference for any virtual shots. The DP should work with the VFX Supervisor, director, and production designer regarding the format and look desired since these will have a direct impact on the visual effects and post-production pipeline.

With the use of previsualization (previs) - which is similar to the storyboard - in preproduction, some DPs are starting to rough-in lighting designs even at this stage. These designs provide them with a guide for lighting the real sets. This information will be useful in the post-production phase if the lighting design remains consistent. The VFX DP will pare in mind some of the issues include film format, capture media (film/digital), color correction, and special equipment requirements (repeatable heads, etc.). The overall look of the images and any required VFX shooting tests should also be discussed with the VFX producer. The VFX Director of Photography plays a major role in the art of visual storytelling. It is the VFX DP's job to make all visual effects elements - be they background plates, miniatures, stunt doubles on a blue screen, aerial photography, or match the look of the 1st Unit DP's photography so that all the elements will ultimately look like they have been photographed together. 
VFX DP will use the previs to:

- Help to drive the process by providing critical input on camera moves, lens choice, and composition.

- Pre-determine equipment needs (including special rigs) early enough to figure budget implications and build what is deemed necessary.

- Predetermine the size of a green screen.

- Design or modify a lighting scheme once lens choices and fields of view are known.

- Perform a virtual prelight, in more advanced systems, using physically accurate models for individual lighting instruments and other main components of the scene.

- Get a sense of the rhythm and coverage of a scene, based on a preliminary previs cut put together by the editorial department. [19]

Doing this job well requires an extraordinarily good creative eye, a thorough understanding of cinematic techniques, and more than a dollop of technical ingenuity. The nature of visual effects usually requires the VFX DP to photograph places, objects, and events under vastly different conditions from those of principal photography. [20]

\section{CONCLUSION}

The Cinematographer role did actually change over the years since the invention of cinema as an art through the days of classic cinema reaching the digital era. The limited crew members at the birth of cinema (usually the director and the camera man and sometimes they were the same person) expanded to be different departments one of them is the special effects department which deals only with the visual effects scenes. In many cases the VFX Director of photography is not the DOP of the entire film; his main job is to shoot the life action part of the visual effects shot, he works more closely with the CG artist to achieve unity of the shot in lighting, perspective and mood and also to keep in mind many other factors, such as the entire film visual continuity and the characteristics of the medium he is using, the difference between film and digital cameras and to be able to come up with solutions to accomplish the shooting and reach the desired result in. The work of VFX DP requires great technical and artistic skills. In fact the cinematographer's role did not diminish but expanded to further aspects.

\section{REFERENCES}

[1] A. J. Mitchell (2004). Visual Effects for Film and Television, Focal Press.

[2] http://www.pbs.org/wgbh/nova/specialfx2/glossary.html\#motion

[3] Charles Zwerman, Susan (2010). The visual effects producer: understanding the art and business of VFX, Focal Press An imprint of Elsevier.

[4] Michael Fink, Jacquelyn Ford Morie (2010). In: The VES handbook of visual effects, Jeffrey A Okun, Susan Zuerman,Visual Effects Society. Published by Elsevier Inc.

[5] Ron Miller (2006). Special Effects: An Introduction to Movie Magic, Lerner Publishing.

[6] Michael Fink, Jacquelyn Ford Morie (2010). In: The VES handbook of visual effects, Jeffrey A Okun, Susan Zuerman, Visual Effects Society. Published by Elsevier Inc.

[7] Richard Ricitt (2007). Special Effects, the History and Technique, Bellboard Books

[8] Richard Ricitt (2007). Special Effects, the History and Technique, Bellboard Books

[9] Michael Fink, Jacquelyn Ford Morie (2010). In: The VES handbook of visual effects, Jeffrey A Okun, Susan Zuerman,Visual Effects Society. Published by Elsevier Inc.

[10] Raymond Fielding (1985). The Technique of Special Effects Cinematography, $4^{\text {th }}$ edition, reprinted 2000, Focal Press.

[11] Michael Fink, Jacquelyn Ford Morie (2010). In: The VES handbook of visual effects, Jeffrey A Okun, Susan Zuerman,Visual Effects Society. Published by Elsevier Inc.

[12] Mark Sawiki (2007).Filming The Fantastic, Focal Press.

[13] Hiroyasu Masuda (2005). Development of a Compact Motion Control Camera System for HD Digital Broadcasting, SMPTE Technical Conference and Exhibition November 9-12, 2005 New York City http://www.nhk.or.jp/digital/en/technical/pdf/01_2_1.pdf 
[14] Charles Zwerman, Susan (2010). The visual effects producer: understanding the art and business of VFX, Focal Press An imprint of Elsevier.

[15] Scott Squires, (2010). Acquisition/Shooting In: The VES handbook of visual effects, Jeffrey A Okun, Susan Zuerman,Visual Effects Society. Published by Elsevier Inc.

[16] Charles Zwerman, Susan (2010). The visual effects producer: understanding the art and business of VFX, Focal Press An imprint of Elsevier.

[17] Mark Sawiki (2007).Filming The Fantastic, Focal Press.

[18] A. J. Mitchell (2004) Visual Effects for Film and Television, Focal Press.

[17] Scott Squires, (2010). Pre-production / Preparation In: The VES handbook of visual effects, Jeffrey A Okun, Susan Zuerman,Visual Effects Society. Published by Elsevier Inc.

[18] Charles Zwerman, Susan (2010). The visual effects producer: understanding the art and business of VFX, Focal Press An imprint of Elsevier. 